WP 0213

\author{
Barbara Annicchiarico \\ University of Rome "Tor Vergata", Italy
}

Alessandra Pelloni

University of Rome "Tor Vergata", Italy

The Rimini Centre for Economic Analysis (RCEA), Italy

\title{
ProduCTIVITY GroWTH AND VOLATILITY: HoW IMPORTANT ARE WAgE AND PRICE RIGIDITIES?
}

Copyright belongs to the author. Small sections of the text, not exceeding three paragraphs, can be used provided proper acknowledgement is given.

The Rimini Centre for Economic Analysis (RCEA) was established in March 2007. RCEA is a private, nonprofit organization dedicated to independent research in Applied and Theoretical Economics and related fields. RCEA organizes seminars and workshops, sponsors a general interest journal The Review of Economic Analysis, and organizes a biennial conference: The Rimini Conference in Economics and Finance (RCEF) . The RCEA has a Canadian branch: The Rimini Centre for Economic Analysis in Canada (RCEACanada). Scientific work contributed by the RCEA Scholars is published in the RCEA Working Papers and Professional Report series.

The views expressed in this paper are those of the authors. No responsibility for them should be attributed to the Rimini Centre for Economic Analysis. 


\title{
Productivity growth and volatility: how important are wage and price rigidities?*
}

\author{
Barbara Annicchiarico $^{\dagger} \quad$ Alessandra Pelloni $^{\ddagger}$
}

December 2012

\begin{abstract}
We study the implications of having different sources of nominal rigidities on the relationship between productivity growth and shocks volatility in a model with procyclical R\&D and imperfect competition in goods and labour markets. We show that the effects of uncertainty on long-term growth not only depends on the source of fluctuations, as recent literature shows, but also, and crucially, on whether prices and/or wages are rigid.

Keywords: Productivity growth, volatility, nominal rigidities, uncertainty.

JEL codes: E32, E52, O42.
\end{abstract}

${ }^{*}$ We would like to thank three anonymous referees, Vincenzo Cuciniello, Holger Strulik, participants at the 2012 Royal Economic Society Annual Conference - University of Cambridge and at the sixth conference on Growth and Business Cycle in Theory and Practice - University of Manchester, 11th Journées Louis-André Gérard-Varet, Aix-Marseille School of Economics and seminar participants at the University of Rome "La Sapienza", University of Rome "Tor Vergata", and Goethe University, Frankfurt for very helpful comments and suggestions on earlier versions of this paper. The usual disclaimer applies.

†Corresponding author: Facoltà di Economia, Università degli Studi di Roma "Tor Vergata", Via Columbia 2, 00133, Roma, Italy. E-mail address: Barbara.Annicchiarico@uniroma2.it.

${ }^{\ddagger}$ Facoltà di Economia, Università degli Studi di Roma "Tor Vergata". E-mail address: Alessandra.Pelloni@uniroma2.it. 


\section{Introduction}

Traditionally macroeconomists considered growth and business cycles as two different fields of research. It wasn't until the Eighties and the seminal papers by Nelson and Plosser (1982) and Kydland and Prescott (1982) that scholars started questioning this view on the grounds that fluctuations are persistent and output does not show a strong tendency to return to its long-run trend after a shock. An explanation for this evidence is provided by endogenous growth models, where any temporary disturbance may affect growth-enhancing activities (i.e. savings, investments, R\&D activities) thus producing everlasting effects on the level of output. ${ }^{1}$ The goal of this paper is to study how different sources of nominal rigidities affect the relationship between short-run fluctuations and productivity growth.

In the presence of market failures business cycles are likely to involve inefficient fluctuations in the allocation of resources, in the sense that the surplus lost from a low level of economic activity during recessions is larger than the gain from a symmetric deviation (see Galí et al. 2007). In a standard New Keynesian model the key distortion producing this effect is market power in the goods and labour markets, which introduces a wedge between the marginal product of labour and the household's marginal rate of substitution between consumption and leisure. As Galí et al. (2007) note, this inefficiency wedge can be decomposed into the product of a price markup (the ratio of the marginal product of labor to the real wage) and a wage markup (the ratio of the real wage to the household's marginal rate of substitution): both these markups will induce a level of employment below its natural rate. In this paper, first, we show analytically how uncertainty will push up both of these markups on average, if there are price and wage rigidities. ${ }^{2}$ This is interesting as a number of authors have shown that price and wage rigidities substantially improve the capacity of DSGE models to match stylized facts. ${ }^{3}$ Second, we show how the inefficiency caused by fluctuations, through their effects on markups, will compound over time. This happens in our model because R\&D activity is positively influenced by the level of employment and aggregate demand which translates into a larger market size for innovations, with permanent effects. ${ }^{4}$

Three sets of basic stylized facts are relevant for this paper: the first one is the existence of nominal rigidities, both in the goods and in the labour markets, the second is the strong procyclicality of both total factor productivity and $R \& D$ and the third refers to the evidence of a relationship between business cycle fluctuations and growth.

Recent direct evidence on price/wage rigidities for developed countries is provided by

\footnotetext{
${ }^{1}$ See Gaggl and Steindl (2007), Steindl and Tichy (2009) and in Aizenman and Pinto (2005) for an overview on the literature.

${ }^{2}$ While New Keynesian contributions are generally made in calibrated models, here we take a complementary line and consider a model with an explicit solution so as to make more transparent the mechanisms at work.

${ }^{3}$ For a complete treatment of the relationship between nominal rigidities and fluctuations, see Bénassy (2002, 2011), while for an introduction to the New Keynesian approach to monetary policy, see Galí (2008). For a recent explanation of how menu and information costs, that agents incur in adjusting prices, may give rise to nominal rigidities, see Alvarez et al. (2011).

${ }^{4}$ In Appendix $\mathrm{C}$ we show that there will be long-run effects of volatility on TFP, even if the assumption on the presence of constant returns to the current level of technology in the innovation activity is dropped, so that sustained growth disappears. We show that in this case uncertainty has level rather than growth effects, but that the mechanisms at work are the same.
} 
Alvarez et al. (2006), Bils and Klenow (2004), Dhyne et al. (2006), Nakamura and Steinsson (2008), Dickens et al. (2007) among others. In general, a marked heterogeneity in the frequency of price adjustment is found across sectors. Further, prices seem to change less frequently in Europe than in the United States. ${ }^{5}$ With reference to wage rigidities, data show that the wages of most workers typically change only annually and depend on a complex set of institutional factors. At the same time microeconomic studies have documented extensive downward nominal wage rigidity in many OECD countries (i.e. Holden and Wulfsberg 2008).

Coming to the second set of facts, there is strong empirical evidence in favour of the procyclicality of R\&D expenses (see e.g. Barlevy 2007, Comin and Gertler 2006 and Walde and Woitek 2004). The positive comovement between R\&D activity and output is a puzzle for theorists, since innovating has a cost in terms of current production, which is likely to be lower during recessions. ${ }^{6}$ A possible explanation for the puzzle is that credit constraints are pervasive and, as a result, R\&D has to be financed by current profits (see e.g. Aghion and Saint-Paul 1998, Aghion and Banerjee 2005, Aghion et al. 2010). The different - but by no means alternative - explanation for the puzzle we incorporate in our model is closer to Fatàs (2000), who shows that exogenous cyclical shocks may have persistent effects on growth through the impact they have on aggregate demand. The mechanism we focus on is the following: $\mathrm{R} \& \mathrm{D}$ activity is stronger during expansions, even if its opportunity cost is higher, because its rewards are higher too, since the innovation creates monopoly power, which however lasts only one period, and will therefore be exploited on a bigger scale when aggregate demand is higher.

With respect to the relationship between business cycle fluctuations and growth, Barlevy (2004) and Comin and Gertler (2006) observe that, over the postwar period, many industrialized countries have experienced significant oscillations between periods of robust growth versus relative stagnation, and suggest that these medium-frequency oscillations may, to a significant degree, be the product of business cycle disturbances at the high frequency. Fatàs (2000) shows that empirical evidence from a large sample of countries suggests that there is indeed a correlation between how persistent fluctuations are and the long-term growth rates of GDP.

Also relevant for our analysis is the empirical evidence on the relationship between uncertainty and growth. Since the seminal paper by Ramey and Ramey (1995), cross-country studies have found that output growth uncertainty has a significant negative relationship with long-run (trend) growth (see Bredin and Fountas 2009, Hnatkovska and Loayza 2005, Kose et al. 2005, Martin and Rogers 2000, Badinger 2010 among many others). However, other empirical analyses, such as Fountas et al. (2006), Grier et al. (2004), Andreou et al. (2012) and Chatterje and Shukayev (2006), suggest that more risky output growth is positively correlated with average output growth, while Grier et al. (2000) find no evidence. On the other hand, there seems to be greater consensus in the empirical literature about the negative relationship between inflation and money supply uncertainty and output growth. ${ }^{7}$

\footnotetext{
${ }^{5}$ For a comprehensive overview on the recent empirical literature spurred by the availability of microprice data, see Klenow and Malin (2010).

${ }^{6}$ The so called Schumpeterian approach has particularly stressed that to the extent that the opportunity cost of $R \& D$ is lower during recessions, these may have a positive impact on growth.

${ }^{7}$ Inflation uncertainty is found to be negatively correlated with output growth by Elder (2004), Fountas et al. (2006), Grier and Perry (2000), Grier et al. (2004) and Judson and Orphanides (1999), however this result does not emerge in Andrés and Hernando (1999); monetary volatility is shown to have negative
} 
Our paper contributes to an expanding theoretical literature that studies the relationship between the business cycle and growth. ${ }^{8}$ A first theory due to Black (1987) points to a positive relationship between uncertainty and growth: when agents may choose from a menu of high-variance, high-expected-returns technologies and low-variance, low-expected-returns technologies, communities with high risk tolerance get high expected returns which imply higher growth at the cost of greater business cycle fluctuations. On the other hand, a high degree of risk aversion will induce more saving and thus more growth in the presence of uncertainty, when there is just one technology available (see Jones et al. 2005). In models where technological change is the result of deliberate (internal) learning or R\&D activity, through actions which substitute production activities, increased uncertainty is likely to enhance the long-run growth prospects of the economy (i.e. Aghion and Saint-Paul 1998 and Blackburn 1999); on the other hand, when technological change is due to serendipitous (external) learning, then higher business cycle volatility is likely to worsen the growth potential (i.e. Martin and Rogers, 1997, 2000). A further ingredient for the generation of a negative relationship between uncertainty and growth are nominal rigidities. In particular, in models with technology à la Romer (1986) and one-period preset wages, Blackburn and Pelloni $(2004,2005)$ show the existence of an unambiguous negative relationship between nominal volatility and growth, while the relationship between real volatility and growth crucially depends on the source of fluctuations and on labour market organization. ${ }^{9}$

A common limit of the papers with nominal rigidities is that no R\&D activity is introduced. This activity is explicitly modelled here. Moreover we study the role of both wage and price rigidities on the relationship between long-term productivity growth and uncertainty due to different sources of stochastic fluctuations (i.e. technology and money supply). We solve the model under the assumption that both wages and prices are set prior to the realizations of the shocks on the basis of one-period-optimal contracts. This is done in the context of a simple stochastic OLG endogenous growth model with imperfect competition in goods and labour markets, where money is the only store value and functions as a medium of exchange.

We find that, in general, the relationship between volatility and productivity growth is negative or null when technological uncertainty predominates, depending on whether prices are predetermined or not. When monetary volatility is concerned instead, we find that under nominal rigidities uncertainty tends to always have a negative effect on long-run productivity growth, but that the strength of this channel crucially depends on the source of nominal rigidities. In the model inflation volatility positively depends on both technological and money volatility, so the model is able to match the empirical evidence on the relationship between growth and inflation volatility, which is mainly found to be negative.

The paper is organized as follows. Section two describes the setup of an OLG stochastic monetary growth model with market power. In Section three we study a benchmark case where prices and wages are set when all shocks have already materialized. In Section four

impact on growth in Andreou et al. (2012) and Turnovsky and Chattopadhyay (2003).

${ }^{8}$ Studies in this literature include Acemoglu and Zilibotti (1997), Francois and Lloyd-Ellis (2003), Jones et al. (2005), Blackburn (1999), Pelloni (1997), de Heck (1999), Canton (2002), Martin and Rogers (1997), Blackburn and Galindev (2003), Blackburn and Varvarigos (2008), Evans and Kenc (2003), Dotsey and Sarte (2000), Varvarigos (2008), Annicchiarico et al. (2011a, 2011b).

${ }^{9}$ Wang and Wei (2011) find a negative relationship in the presence of extrinsic uncertainty using an AK model with variable capacity utilization and price setting by monopolistic firms. 
we derive the relationship between long-term productivity growth and volatility under the assumption of different sources of nominal rigidities: (i) preset wages, (ii) preset prices, (iii) preset prices and wages. Finally, some concluding comments are offered in Section five.

\section{A simple endogenous growth model with procyclical R\&D and market power}

There is a continuum of firms indexed by $j \in[0,1]$ operating in a monopolistically competitive market. Productivity is endogenously determined and depends on the R\&D activity of firms. The demand side is described by a two-period overlapping generations monetary model. The labour market is characterized by the presence of a monopolistic union setting nominal wages, whereby firms determine the level of employment. Time is discrete and indexed by $t \in\{0,1, \ldots \infty\}$.

\subsection{Firms}

Each firm produces a differentiated good $Y_{t}(j)$ by combining $L_{Y, t}(j)$ units of labour according to the following technology:

$$
Y_{t}(j)=A_{t}(j) L_{Y, t}(j)^{\alpha}, \alpha \in(0,1),
$$

where $A_{t}(j)$ is firm's $j$ total factor productivity (TFP) given by the stock of knowledge at its disposal. By doing R\&D firms can increase their TFP in the current period:

$$
A_{t}(j)=\Omega_{t} A_{t-1} L_{R D, t}^{\phi}(j)
$$

with

$$
\begin{gathered}
\Omega_{t}=\Omega \exp \left(\varepsilon_{\Omega, t}-\frac{\sigma_{\Omega}^{2}}{2}\right), \varepsilon_{\Omega, t} \sim \operatorname{iid.N}\left(0, \sigma_{\Omega}^{2}\right), \\
\Omega>1, \phi \in(0,1), \alpha+\phi<1,
\end{gathered}
$$

where $L_{R D, t}(j)$ is the quantity of labour inputs devoted to the R\&D activity, $A_{t-1}$ is publicly available (that is the productivity of individual firm's R\&D activity increases with the stock of technology). According to equation (2) at the beginning of period $t$, starting from a common level of productivity $A_{t-1}$, each firm can raise its productivity by devoting labour inputs to $R \& D$ activity. Putting it in another way, equation (2) captures the so called "standing on shoulders" effect of knowledge accumulation, indicating that the productivity of researchers increases with the stock of ideas that have already been discovered. We also assume that the monopoly power of the firm over the results of its innovative activity only lasts one period. This simplification, also adopted by Strulik et al. (2011) avoids intertemporal (dynastic) problems of patent holding, but keeps the basic incentive to create new knowledge intact. The specification of the exogenous variable $\Omega_{t}$ implies that $E\left(\Omega_{t}\right)=\Omega$ and therefore enables us to capture the pure effect of volatility. ${ }^{10}$

\footnotetext{
${ }^{10} \mathrm{An}$ increase in $\sigma_{\Omega}^{2}$, in fact, implies an increase in the variance of $\Omega_{t}$, which is found to be $\Omega^{2}\left[\exp \left(\sigma_{\Omega}^{2}\right)-1\right]$, leaving its mean unchanged, since $E\left[\exp \left(\varepsilon_{\Omega, t}-\frac{\sigma_{\Omega}^{2}}{2}\right)\right]=1$.
} 
A more general formulation than (2) for the productivity process would be: $A_{t}(j)=$ $\Omega_{t} A_{t-1}\left[L_{R D, t}^{\phi}(j)+1-\delta_{A}\right]$, where $\delta_{A}$ can be interpreted as the obsolescence rate of technical knowledge and $1-\delta_{A}$ as the survival probability of technologies. ${ }^{11}$ With $\delta_{A}=1$ we get our specification. The assumption of $100 \%$ depreciation of accumulable factors, used for physical capital by Long and Plosser (1983) to build an analitically solvable stochastic Ramsey model, is rather common in works on growth and volatility. It can be found as regards the accumulation of technology in Blackburn and Galindev (2003) and as regards the accumulation of human capital in Jones et al. (2005) and in Varvarigos (2010). ${ }^{12}$

Equation (2) also assumes constant returns to the level of technology in the innovation activity. This assumption generates long-run growth in the model. An implication of this assumption is, however, that larger economies would grow at a faster rate and that an increasing population would trigger explosive growth. In Jones (2005) parlance the model exhibits 'strong' scale effects. In Appendix $\mathrm{C}$ we extend our analysis to the case in which the assumption is dropped, so that the model only delivers level ('weak') rather than growth scale effects.

Finally, parameter $\phi$ in (2) is less than one in order to capture the possibility of decreasing returns to labour in $\mathrm{R} \& \mathrm{D} .^{13}$

Firm $j$ faces a demand function of the form:

$$
Y_{t}(j)=\left(\frac{P_{t}(j)}{P_{t}}\right)^{-\theta} Y_{t},
$$

where $P_{t}$ is the aggregate price level, $Y_{t}$ aggregate production, $P_{t}(j)$ the price of good $j$ and $\theta>1$ the elasticity of substitution between any pair of goods. Firm's $j$ will set $L_{Y, t}(j)$ and $L_{R D, t}(j)$ so as to equate their marginal product. Moreover firms are assumed to be symmetric so we can drop the index $j$. At an optimum, writing $L_{t}=L_{R D, t}+L_{Y, t}$, we have:

$$
\begin{gathered}
L_{R D, t}=\frac{\phi}{\alpha} L_{Y, t}, \\
Y_{t}=\Psi \Omega_{t} A_{t-1} L_{t}^{\alpha+\phi},
\end{gathered}
$$

where $\Psi \equiv[\phi /(\alpha+\phi)]^{\phi}[\alpha /(\alpha+\phi)]^{\alpha}$ and

$$
L_{R D, t}=\phi L_{t} /(\alpha+\phi) .
$$

The condition for the optimal price is contingent on the timing of its fixing, so we will consider it later.

\footnotetext{
${ }^{11}$ Comin and Gertler (2006) posit a annual rate of obsolescence of 0.03 .

${ }^{12}$ In fact with this formulation technical regress is possible in principle, even if its probability will be low if the coefficient of variation of the shocks is low. This possibility is also an implication of the representation of the (exogenous) evolution of technology in many DSGE models. In these models, in fact, the technology shifter in the aggregate production function (see e.g. King and Rebelo 1999) is often represented as an exogenous autoregressive process with drift. Such a process can in principle deliver technology regress when the disturbance term is negative enough.

${ }^{13}$ In reality, there could also be an externality due to the duplication of research activity taking place in other firms. This so called "stepping on toes" effect could induce an even stronger curvature of the aggregate knowledge production function with respect to labour.
} 


\subsection{Households}

The typical household born at time $t$ supplies labour $N_{t}$, consumes $C_{t}$ in period $t$ and $C_{t+1}^{\prime}$ in period $t+1$. The expected value of lifetime utility is

$$
U_{t}=E_{t}\left(\log C_{t}+\frac{1}{\gamma} \log C_{t+1}^{\prime}-\eta \frac{1}{v} N_{t}^{v}\right), \quad \gamma>1, v>1, \eta>0
$$

where $C_{t}$ is a consumption index given by $C_{t} \equiv\left[\int_{0}^{1} C_{t}(j)^{\frac{\theta-1}{\theta}} d j\right]^{\frac{\theta}{\theta-1}}$ with $C_{t}(j)$ being the quantity consumed of good $j, 1 / \gamma$ is the discount factor and $\eta$ weights the disutility of working. To simplify the algebra and without loss of generality, we set the coefficient in the disutility of labour such that $\eta \equiv(1+\gamma) / \gamma$. With reference to labour inputs, the above formulation has three main implications: (i) preferences are consistent with balanced growth, in the sense that in BGP doubling a household's income doubles its consumption, but does not affect its labour inputs choice; (ii) the marginal utility of consumption is independent of the worker's leisure; (iii) the Frisch elasticity of labour supply is constant and equal to $1 /(v-1)$. The formulation is popular in the New Keynesian literature (see e.g. Galí 2008) and in theoretical contributions relying on analytical solutions (see Bénassy 2002, 2011) as it enhances tractability.

At the optimum the demand for each good $j \in[0,1]$ is $C_{t}(j)=\left(P_{t}(j) / P_{t}\right)^{-\theta} C_{t}$, where $P_{t}=\left[\int_{0}^{1} P_{t}(j)^{1-\theta} d j\right]^{\frac{1}{1-\theta}}$. It follows that $\int_{0}^{1} P_{t}(j) C_{t}(j)=P_{t} C_{t}$. Households save in the form of money (at time $t$, denoted by $M_{t}$ ) which is the unique asset of the economy. Their budget constraints in the two periods are given by:

$$
\begin{gathered}
P_{t} C_{t}+M_{t}=W_{t} N_{t}+\Pi_{t}, \\
P_{t+1} C_{t+1}^{\prime}=\mu_{t+1} M_{t}, \\
\mu_{t}=\mu \exp \left(\varepsilon_{\mu, t}-\frac{\sigma_{\mu}^{2}}{2}\right), \mu>1, \varepsilon_{\mu, t} \sim \text { iid.N }\left(0, \sigma_{\mu}^{2}\right),
\end{gathered}
$$

where $\Pi_{t}$ denotes firms' nominal profits, $\mu_{t}$ is a stochastic multiplicative monetary shock and $\varepsilon_{\mu, t}$ is a monetary innovation. ${ }^{14}$

The representative household will choose $C_{t}$ and $C_{t+1}^{\prime}$ to maximize (8) subject to the budget constraints (9) and (10). By using the fact that in general equilibrium all markets must clear, so that $C_{t}+C_{t}^{\prime}=Y_{t}$ and $M_{t}=H_{t}$, with $H_{t}$ being money supply which evolves as $H_{t}=\mu_{t} H_{t-1}$, we have that (10) can be rewritten as $P_{t} C_{t}^{\prime}=M_{t}$, so that money is entirely held by the old who spend all of it. The consumption function of the young is then found to be

$$
C_{t}=\frac{\gamma}{1+\gamma} Y_{t}
$$

and the condition for the money market equilibrium is

$$
\frac{M_{t}}{P_{t}}=\frac{Y_{t}}{1+\gamma}
$$

\footnotetext{
${ }^{14}$ For simplicity we assume that households start off with no money. This assumption is not crucial for our results and is consistent with the role of money as a reserve value and a medium of exchange.
} 


\section{$3 \quad$ Volatility and growth with flexible prices and wages}

In this Section we present the remaining equilibrium conditions and model solution under the assumption that both wages and prices are flexible. By 'flexibility' we mean that the current realizations of the shocks are observed when prices and wages are set.

Firm's $j$ will set $P_{t}(j)$ to maximise current profits $\Pi_{t}(j)=P_{t}(j) Y_{t}(j)-W_{t}\left[L_{Y, t}(j)+L_{R D, t}(j)\right]$ given the wage $W_{t}$, the demand for its own good (4) and the technology equations (1) and (2). We have already seen that (5) and (6) will hold. A further optimizing condition dictates that the optimal price will correspond to a markup over the marginal cost

$$
P_{t}=\Theta \frac{W_{t} L_{t}}{(\alpha+\phi) Y_{t}}
$$

again omitting the $j$ index to save on notation and with $\Theta \equiv \theta /(\theta-1)$. Clearly, when prices are set after the realizations of the shocks the price markup, which we label $\mathcal{M U}^{P}$ for future reference, is always constant and equal to $\Theta$. Finally, using (6) and (14) we can express labour demand as

$$
L_{t}=\left(\frac{\Theta}{\alpha+\phi} \frac{W_{t}}{\Psi \Omega_{t} P_{t} A_{t-1}}\right)^{-\frac{1}{1-(\alpha+\phi)}} .
$$

Coming to the labour market functioning, we adopt a "right to manage" assumption: a monopolistic trade union sets the nominal wage in order to maximise households' expected utility (8), given labour demand (15). As hinted above, we distinguish between the case in which this is done after the current shock is revealed (the "flexible wages" case), and the case in which this is done before ("preset wages" case), presented in the next section. Given (15), at the optimum we have:

$$
\frac{W_{t}}{P_{t}}=\frac{1}{\alpha+\phi} \frac{(1+\gamma) L_{t}^{v-1} C_{t}}{\gamma},
$$

where we have used the fact that in equilibrium $L_{t}=N_{t}$.

Notice that market power in the labour market introduces a wedge between the real wage rate, $W_{t} / P_{t}$, and the marginal rate of substitution between leisure and consumption, $[(1+\gamma) / \gamma] L_{t}^{v-1} C_{t}$. Henceforth, we will refer to this wedge as the wage markup labeled as $\mathcal{M} \mathcal{U}^{W}$. This is constant and equal to $(\alpha+\phi)^{-1}$ when wages are set after all shocks have materialized.

By combining (16) with (15) and using (12), the equilibrium level of employment is then found to be:

$$
L_{t}=\bar{L} \equiv\left[\frac{(\alpha+\phi)^{2}}{\Theta}\right]^{1 / v} .
$$

From (17) the equilibrium level of employment is increasing in the elasticity of production with respect to labor $\alpha+\phi$ and in the elasticity of substitution between intermediates $\theta$, i.e. decreasing in the market power of producers. Finally, employment is higher the lower is the Frisch elasticity of labour supply $1 /(v-1)$. Notice that neither nominal nor technological shocks have an effect. For the former this is not surprising as with price and wage flexibility money is a veil. For technological shocks, this depends on preferences: an increase in the 
real wage brought about for instance by a positive technology shock through an increase in labor demand has offsetting income and substitution effects, so that labour supplied does not change. So a technology shock will have a positive effect on income and the real wage and a negative effect on prices, with no effect on employment. By combining (14), (13) and (16), while considering (17), we note that the nominal wage will stay put in the face of a technological shock, a fact which will be exploited for interpreting the reaction of the economy to a technological shock when wages are preset.

Let $g_{A} \equiv \Omega[\phi \bar{L} /(\alpha+\phi)]^{\phi}$ denote the deterministic growth rate of productivity, ${ }^{15}$ i.e. the growth rate prevailing in the absence of shocks. Due to the fact that productivity growth is a linear function of the technological shocks and is not affected by money shocks, we can immediately infer the following:

Proposition 1 In the absence of nominal rigidities the equilibrium growth rate of productivity between two consecutive periods and its average are given by:

$$
\begin{gathered}
\frac{A_{t}}{A_{t-1}}=\Omega_{t}\left(\frac{\phi}{\alpha+\phi} \bar{L}\right)^{\phi}, \\
E\left(\frac{A_{t}}{A_{t-1}}\right)=g_{A} \equiv \Omega[\phi \bar{L} /(\alpha+\phi)]^{\phi},
\end{gathered}
$$

implying that long-run growth is not affected by shocks volatility.

Proof. Using $L_{R D, t}=\phi L_{t} /(\alpha+\phi)$ in $A_{t}=\Omega_{t} A_{t-1} L_{R D, t}^{\phi}$, given (17), delivers the result (18). Taking expectations, given (3), yields (19).

Summing up, without nominal rigidities, long-run growth is not affected by uncertainty. Producers and unions, in fact, set prices and wages after the shocks have materialized, being so able to keep price and wage markups at the desired optimal levels, i.e. $\Theta$ and $(\alpha+\phi)^{-1}$, as implied by equations (14) and (16).

Our model also has predictions on the distribution of inflation, as reported in Appendix B. In particular we show that, in all the different cases we consider as regards price and wage flexibility, the variance of inflation is increasing in real and nominal volatility. Moreover, again in all cases, the model predicts a positive relationship between the average and the variance of inflation, whose size, however, changes with the source of volatility and the nature of the nominal rigidities. ${ }^{16}$

\footnotetext{
${ }^{15}$ It can be easily shown that by removing producers and unions market power from the economy, the deterministic growth rate of productivity will be $g_{A} \equiv \Omega[\phi /(\alpha+\phi)]^{\phi}(\alpha+\phi)^{\phi / v}$, being $L_{t}=(\alpha+\phi)^{1 / v}$ the equilibrium level of employment which differs from (17) by two constant factors of proportionality: $(\alpha+\phi)^{1 / v}$ and $(1 / \Theta)^{1 / v}$, the first one reflecting the effect of monopolistic wage setting and the second one the inefficiency of the monopolistic competition in the final goods market. The presence of market power leads, in fact, to underemployment and low growth.

${ }^{16}$ The link between inflation and its uncertainty is the focus of the positive theories of inflation, where the behaviour of the central banker is explicitly modelled. For a complete overview see Walsh (2003, chap. 8). Seminal papers are Devereux (1987) and Cukierman and Meltzer (1986), among many others. Devereux (1987) shows that if the degree of wage indexation is inversely related to uncertainty, there is an incentive for the monetary authorities to create surprise inflation. In Cukierman and Meltzer (1986) the positive relationship between the mean and variance of inflation arises from the fact the the public is uncertain about the central bank's true preferences.
} 


\section{Volatility and growth with nominal rigidities}

In this Section we study, in turn, the case of preset wages, preset prices and preset prices and wages.

\subsection{Preset wages}

Consider the case in which in each period monopolistic unions set the nominal wage prior to the realizations of the shocks, so as to maximise the expected utility function of those working in the period (i.e. the young) given firms labour demand (15). The optimal nominal wage set at the beginning of period $t$ is such that

$$
W_{t}=\frac{1}{\alpha+\phi} \frac{(1+\gamma) E_{t-1} L_{t}^{v}}{\gamma E_{t-1}\left(\frac{L_{t}}{P_{t} C_{t}}\right)} .
$$

In equilibrium the nominal wage, employment and its mean are then seen to be (see Appendix A for the full derivation):

$$
\begin{gathered}
W_{t}=\frac{(1+\gamma)(\alpha+\phi)}{\Theta} \bar{L}^{-1} M_{t-1} \mu\left[\exp (v-1) \frac{\sigma_{\mu}^{2}}{2}\right], \\
L_{t}=\bar{L} \frac{\mu_{t}}{\mu} \exp \left[-(v-1) \frac{\sigma_{\mu}^{2}}{2}\right],
\end{gathered}
$$

so that:

$$
E\left(L_{t}\right)=\bar{L} \exp \left[-(v-1) \frac{\sigma_{\mu}^{2}}{2}\right]
$$

This yields:

Lemma 1 When wages are preset on the basis of one-period contract before the realizations of the shocks, the nominal wage is increasing in money volatility while equilibrium employment (and its average) is decreasing in it.

Proof. From inspection of (21) and (22), recalling that $v>1$.

Not surprisingly from what we know from the analysis of the case of wage flexibility, technology shocks have no effect on labour. We have seen, in fact, that a technology shock would not imply any change in the nominal wage, even if the wage were free to move. So basically nothing changes with respect to the previous case as regards technological uncertainty. ${ }^{17}$ As a contrast, the nominal wage is increasing in money volatility, and, through labour demand, employment (and its expected value) are correspondingly decreasing in it. To understand these effects intuitively consider that, while under certainty the marginal rate of substitution between consumption and leisure is always equal to the real wage (bar the constant monopoly wedge), under uncertainty people will have to work more (i.e. at a higher marginal rate of substitution) when the real wage is lower and less when the real wage is higher. The way to reduce these deviations from the (private optimum) is to make them happen around a lower average level of employment (so the increases and decreases in the marginal disutility of labor will be smaller) and therefore set a higher nominal wage. In

\footnotetext{
${ }^{17}$ This result is consistent with the findings of Blackburn and Pelloni (2005).
} 
fact, it can be easily shown that on average the wage markup will be higher, the higher the level of monetary uncertainty (see Appendix A for details):

$$
E\left(\mathcal{M U}_{t}^{W}\right)=\frac{1}{\alpha+\phi} \exp \left(v^{2} \sigma_{\mu}^{2}\right) .
$$

The presence of the wage friction is then a source of economic inefficiency made worse by volatility. The size of the effect depends on the preference parameter $v$. The higher is $v$, in fact, the lower is the Frisch elasticity of labour supply. In the limiting case where $v=1$, a mean preserving spread increase in money uncertainty will leave expected employment unchanged. Conversely, higher $\alpha$ and $\phi$ will reduce the positive effect of money volatility on the expected markup. This is because the marginal productivity of labour and, therefore, the real wage will be less influenced by changes in employment, the higher these parameters are. From the above results we have the following proposition:

Proposition 2 When wages are preset on the basis of one-period contract before the realizations of the shocks, the equilibrium growth rate of productivity and its average are given by:

$$
\begin{aligned}
\frac{A_{t}}{A_{t-1}}=\Omega_{t}\left(\frac{\phi}{\alpha+\phi} \bar{L}\right)^{\phi}\left(\frac{\mu_{t}}{\mu}\right)^{\phi} \exp \left[-\phi(v-1) \frac{\sigma_{\mu}^{2}}{2}\right], \\
E\left(\frac{A_{t}}{A_{t-1}}\right)=g_{A} \exp \left[-\phi(v-\phi) \frac{\sigma_{\mu}^{2}}{2}\right],
\end{aligned}
$$

Proof. Using $L_{R D, t}=\phi L_{t} /(\phi+\alpha)$ and (22) into $A_{t}=\Omega_{t} A_{t-1} L_{R D, t}^{\phi}$ delivers the result (25). Taking expectations, given (11) and (3), delivers (26).

From (25) we notice that the equilibrium growth rate of productivity is a linear function of $\Omega_{t}$, as in the previous case with flexible wages. On the other hand, an increase in money supply in period $t$ has now a positive effect on growth, through the effect that a monetary surprise has on aggregate demand and so on employment (22) and TFP growth (since R\&D activity is procyclical). In this context, the effect of money volatility on long-run growth is negative, while the effect of technology volatility is null. Since the rate of technology growth is linear in technology shocks, its expected value is not influenced by their volatility. The negative effect of money volatility is mediated by the effect on employment and, in particular, by the degree of disutility deriving from non-leisure activity, measured by the parameter $v$, on which the Frisch elasticity of labour supply depends inversely, and by the parameter $\phi$. However, the effect of $\phi$ is two-fold: on the one hand a higher value of $\phi$ has a moderating influence on the wage markup and, therefore, limits the negative effect of money volatility on average employment and so on average productivity growth, which is an increasing function of labour. On the other hand, a higher value of $\phi$ implies a stronger contribution of labour to innovation and so a more detrimental effect of lower employment on productivity growth.

\subsection{Preset prices}

We now introduce nominal rigidities in the form of preset prices, while moving back to the assumption of flexible wages. Producers set prices for period $t$ before observing the 
realizations of the shocks in order to maximise expected profits. At time $t-1$ firm $j$ will set the price $P_{t}(j)$ in order to maximise the expected profit, $E_{t-1} \Pi_{t}(j)$, subject to the technological constraints represented by (1), (2) and (4) and given the wage $W_{t}$. First notice that (5) and therefore (6) are still valid, as necessary conditions for optimality. Under symmetry of firms, the optimal pricing decision taken at time $t-1$ is then:

$$
P_{t}=\frac{\Theta E_{t-1} W_{t} L_{t}}{(\alpha+\phi) E_{t-1} Y_{t}}
$$

which now replaces (14), which holds only if prices are flexible. In equilibrium we then have (see Appendix A):

$$
\begin{gathered}
P_{t}=\frac{\bar{L}^{-(\alpha+\phi)}(1+\gamma) \mu M_{t-1}}{\Psi \Omega A_{t-1}} \exp \left[\frac{\alpha+\phi+v}{\alpha+\phi}\left(\frac{\sigma_{\mu}^{2}}{2}+\frac{\sigma_{\Omega}^{2}}{2}\right)\right], \\
L_{t}=\bar{L}\left(\frac{\Omega}{\mu} \frac{\mu_{t}}{\Omega_{t}}\right)^{\frac{1}{\alpha+\phi}} \exp \left[-\frac{\alpha+\phi+v}{(\alpha+\phi)^{2}}\left(\frac{\sigma_{\mu}^{2}}{2}+\frac{\sigma_{\Omega}^{2}}{2}\right)\right],
\end{gathered}
$$

and, taking expectations:

$$
E\left(L_{t}\right)=\bar{L} \exp \left[-\frac{v-1}{(\alpha+\phi)^{2}}\left(\frac{\sigma_{\mu}^{2}}{2}+\frac{\sigma_{\Omega}^{2}}{2}\right)-\frac{1}{\alpha+\phi} \sigma_{\mu}^{2}\right] .
$$

This yields:

Lemma 2 When prices are preset on the basis of one-period contracts before the realizations of the shocks, the price level are increasing in money and technological volatilities, while equilibrium employment (and its mean) are decreasing in them.

Proof. From inspection of (28)-(30).

From (29) employment depends on both the realizations and the variances of the shocks. Since nominal wages are flexible, they will react to all changes in technology and money supply. Positive money shocks will translate into higher employment and positive technology shocks into lower employment. This is because an unexpected monetary expansion, with given prices, pushes demand up and so output and employment increase even more than with fixed nominal wages. On the other hand, a positive technological innovation increases total factor productivity in (2), but leads to an employment decline, because price rigidities prevent an increase in aggregate demand, given the quantity of money: the same production will then be obtained with less labor.

A higher level of volatility, whatever its source, is always harmful to employment. To understand why, let us consider the effect of volatility on price markups. While the wage markup will be constant and equal at $(\alpha+\phi)^{-1}$, price markups will now depend on the realizations of the shocks and on their variances. From the convexity of both the cost function of firms and of the labour disutility function of workers, higher uncertainty in production and employment implies higher expected marginal costs and so a higher price level. On average firms' price markup is found to be (see Appendix A):

$$
E\left(\mathcal{M U}_{t}^{P}\right)=\Theta \exp \left[\left(\frac{v}{\alpha+\phi}\right)^{2} \sigma_{\Omega}^{2}+v \frac{v+\alpha+\phi}{(\alpha+\phi)^{2}} \sigma_{\mu}^{2}\right]
$$


which is clearly higher than its deterministic counterpart $\Theta$.

The effect of volatility on the price markup is weaker the higher the elasticity of the aggregate production function with respect to labour $(\alpha+\phi)$ and the higher the elasticity of labor supply. It is worth noting that for $v=1$ a mean preserving spread increase in nominal volatility will still have negative effect on employment contrary to the case of preset wages analyzed in the previous section. The effect of money volatility is stronger than the effect of technology volatility: this is because with money volatility firms will have to produce more (less) just when the real wage is higher (lower), as nominal wages are free to move procyclically: this will increase the convexity of the firms' cost function in general equilibrium that is when taking into account the reaction of the wage. With technological volatility real wages move in the opposite direction to employment which flattens the cost curve with respect to the case of money volatility.

Given the above results we have:

Proposition 3 When prices are preset on the basis of one-period contract before the realizations of the shocks, the equilibrium growth rate of productivity and its average are given by:

$$
\begin{gathered}
\frac{A_{t}}{A_{t-1}}=\Omega_{t}\left(\frac{\phi}{\alpha+\phi} \bar{L}\right)^{\phi}\left(\frac{\Omega}{\mu} \frac{\mu_{t}}{\Omega_{t}}\right)^{\frac{\phi}{\alpha+\phi}} \exp \left[-\phi \frac{\alpha+\phi+v}{(\alpha+\phi)^{2}}\left(\frac{\sigma_{\mu}^{2}}{2}+\frac{\sigma_{\Omega}^{2}}{2}\right)\right], \\
E\left(\frac{A_{t}}{A_{t-1}}\right)=g_{A} \exp \left[-\phi \frac{2 \alpha+\phi+v}{(\alpha+\phi)^{2}}\left(\frac{\sigma_{\mu}^{2}}{2}+\frac{\sigma_{\Omega}^{2}}{2}\right)\right] .
\end{gathered}
$$

Proof. Using $L_{R D, t}=\phi L_{t} /(\phi+\alpha)$ and (29) into $A_{t}=\Omega_{t} A_{t-1} L_{R D, t}^{\phi}$ gives us (32). Taking expectations given (3) and (11), gives us (33).

Recalling the results of Proposition 2, we notice that nominal volatility is more detrimental to productivity growth under preset prices than under preset wages, as $\phi(v-\phi)<$ $\phi \frac{2 \alpha+\phi+v}{(\alpha+\phi)^{2}}$. Moreover we have a negative effect of technology volatility, which was absent in the previous case. All these effects work through employment which is inefficiently low as a result of price rigidities.

\subsection{Preset prices and wages}

Finally, we solve the model of Section 2 under the assumption that both prices and wages are set on the basis of one-period contract before observing the shocks. In this case the optimal price and wage decided at time $t-1$ are

$$
P_{t}=W_{t} \frac{\Theta}{\alpha+\phi} \frac{E_{t-1} L_{t}}{E_{t-1} Y_{t}}
$$

and

$$
W_{t}=\frac{P_{t}}{\alpha+\phi} \frac{(1+\gamma) E_{t-1} L_{t}^{v}}{\gamma E_{t-1}\left(\frac{L_{t}}{C_{t}}\right)} .
$$

The above equations now replace (14) and (16), implying that the real wage is now preset at time $t-1$. In equilibrium prices, wages, employment and its mean are (see Appendix $\mathrm{A}$ 
for the full derivation):

$$
\begin{gathered}
P_{t}=\frac{\bar{L}^{-(\alpha+\phi)}(1+\gamma) \mu M_{t-1}}{\Psi \Omega A_{t-1}} \exp \left[\frac{\alpha+\phi+v}{\alpha+\phi}\left(\frac{\sigma_{\mu}^{2}}{2}+\frac{\sigma_{\Omega}^{2}}{2}\right)-B \frac{\sigma_{\mu}^{2}}{2}\right], \\
W_{t}=\frac{\alpha+\phi}{\Theta}(1+\gamma) \bar{L}^{-1} \mu M_{t-1} \exp \left[\frac{v-1}{(\alpha+\phi)^{2}}\left(\frac{\sigma_{\mu}^{2}}{2}+\frac{\sigma_{\Omega}^{2}}{2}\right)+\frac{1-\alpha-\phi}{v(\alpha+\phi)} \sigma_{\mu}^{2}\right], \\
L_{t}=\bar{L}\left(\frac{\mu_{t} \Omega}{\mu \Omega_{t}}\right)^{\frac{1}{\alpha+\phi}} \exp \left[-\frac{\alpha+\phi+v}{(\alpha+\phi)^{2}}\left(\frac{\sigma_{\mu}^{2}}{2}+\frac{\sigma_{\Omega}^{2}}{2}\right)+\frac{B}{\alpha+\phi} \frac{\sigma_{\mu}^{2}}{2}\right], \\
E\left(L_{t}\right)=\bar{L} \exp \left[-\frac{v-1}{(\alpha+\phi)^{2}}\left(\frac{\sigma_{\mu}^{2}}{2}+\frac{\sigma_{\Omega}^{2}}{2}\right)-\frac{1-\alpha-\phi}{v(\alpha+\phi)} \sigma_{\mu}^{2}\right],
\end{gathered}
$$

where $B \equiv 2\{1-[1-(\alpha+\phi)] / v\}>0$.

The above expressions deliver the following result:

Lemma 3 When both prices and wages are preset on the basis of one-period contract before the realizations of the shocks an increase in money and technological uncertainty has a positive effect on the equilibrium price and wage levels and a negative one on employment and its mean.

Proof. From inspection of (36), (37) and (38) and by noting that $-[1+v /(\alpha+\phi)]+B<0$.

Notice the effect on nominal wages is stronger for nominal uncertainty than for real uncertainty. To gain intuition as to why we observe the above results consider the markups. We have:

$$
E\left(\mathcal{M U}^{P}\right)=\Theta \exp \left[\frac{1}{(\alpha+\phi)^{2}} \sigma_{\Omega}^{2}+\frac{1-\alpha-\phi}{(\alpha+\phi)^{2}} \sigma_{\mu}^{2}\right]
$$

and

$$
E\left(\mathcal{M U}^{W}\right)=\frac{1}{\alpha+\phi} \exp \left[\frac{v(v-1)}{(\alpha+\phi)^{2}} \sigma_{\Omega}^{2}+\frac{v(v+\alpha+\phi-1)}{(\alpha+\phi)^{2}} \sigma_{\mu}^{2}\right] .
$$

Derivations are in Appendix A. It can be easily seen that, again, both price and wage markups are higher on average than without uncertainty. However the price markup is lower than when nominal wages are flexible, so to some extent, the two kinds of frictions offset each other. This is because with fixed nominal wages, the elasticity of labour supply is no longer relevant as regards the movements of the real wage over the business cycle. Higher volatility of employment implies higher expected marginal costs for firms and therefore a higher price level. However, the convexity of the cost function of firms is now reduced by the fact that nominal wages cannot move procyclically, so that firms' marginal costs tend to be more stable. Conversely, the wage markup is higher than when prices are flexible. First of all, since a technology shock does not influence the real wage but does push employment up or down, to minimize the deviations of the marginal rate of substitution from its (privately) optimal level, the average labour supply moves down in the face of increased technological uncertainty, an effect that was absent with predetermined wages and flexible prices. Moreover, the effect of money uncertainty on the wage markup is also higher than with flexible prices, (just by 
comparing (24) and (41) and noticing that $\left.\frac{v(v+\alpha+\phi-1)}{(\alpha+\phi)^{2}}>v^{2}\right)$. In fact, with preset prices an increase in aggregate demand will not be (partially) absorbed by inflation, so employment will fluctuate more. Unions will then find it optimal to set a higher nominal wage, so that the gap between the marginal rate of substitution between consumption and leisure and the real wage is smaller.

From the above analysis, this result immediately follows:

Proposition 4 When both prices and wages are preset on the basis of one-period contract before the realizations of the shocks, the equilibrium growth rate of productivity and its average are given by:

$$
\frac{A_{t}}{A_{t-1}}=\Omega_{t}\left(\frac{\phi}{\alpha+\phi} \bar{L}\right)^{\phi}\left(\frac{\mu_{t} \Omega}{\mu \Omega_{t}}\right)^{\frac{\phi}{\alpha+\phi}} \exp \left[-\phi \frac{\alpha+\phi+v}{(\alpha+\phi)^{2}}\left(\frac{\sigma_{\mu}^{2}}{2}+\frac{\sigma_{\Omega}^{2}}{2}\right)+\phi \frac{B}{\alpha+\phi} \frac{\sigma_{\mu}^{2}}{2}\right],
$$

and

$$
E\left(\frac{A_{t}}{A_{t-1}}\right)=g_{A} \exp \left[-\phi \frac{2 \alpha+\phi+v}{(\alpha+\phi)^{2}}\left(\frac{\sigma_{\mu}^{2}}{2}+\frac{\sigma_{\Omega}^{2}}{2}\right)+\phi \frac{B}{\alpha+\phi} \frac{\sigma_{\mu}^{2}}{2}\right]
$$

Proof. Using $L_{R D, t}=\phi L_{t} /(\phi+\alpha)$ and (38) into $A_{t}=\Omega_{t} A_{t-1} L_{R D, t}^{\phi}$ delivers (42). the first result. Then take expectations, given (3) and (11) and note that $-\frac{2 \alpha+\phi+v}{\alpha+\phi}+B<0$.

From (43) it should be noted that the coefficient on real volatility is as in (33), since it is only through price stickiness that technology uncertainty reflects on employment and hence on growth. As regards money volatility, we note that the the effect of nominal uncertainty is lower than when only prices are sticky by virtue of the more muted response of real marginal costs to money shocks.

\section{Conclusions}

In this paper we construct an analytically solvable monetary model with endogenous growth driven by $R \& D$ to study the effect of wage and price rigidities on the relationship between long-term productivity growth and short-term volatility. We find that both nominal and real uncertainty may be harmful to secular growth, in the presence of nominal rigidities.

In the model, R\&D is more profitable the higher the level of economic activity. This explains its observed procyclicality. On its turn, the level of economic activity is reduced by market power by firms and workers, as this inserts a wedge between the marginal product of labour and the marginal rate of substitution between leisure and consumption. We show that price and wage rigidities induce fluctuations in this wedge making it higher on average than its deterministic counterpart. We analyse how price and nominal wage distortions interact with each other in propagating real and nominal shocks. In particular, we show that the effects on growth depend critically on the source of uncertainty and on the type of nominal rigidities. From this point of view, we argue that the frequency of price and wage changes across countries may influence the way in which uncertainty impacts productivity growth.

The main contribution of this paper lies in highlighting the importance of nominal rigidities as a possible conditioning factor for the effects of uncertainty on growth. At the same 
time we recognize that many important channels studied in the literature on growth and volatility are absent from our model, which was kept deliberately simple. However, as there is no reason for presupposing that growth should occur on the basis of one mechanism alone, we plan in further research to embody the effect that uncertainty may have on pricing decisions, which is the exclusive focus of this paper, in a more general model, which might be able to match the empirical evidence along more dimensions than the one presented here.

\section{References}

[1] Acemoglu, D. 2009. Introduction to modern economic growth. Princeton University Press, Princeton and Oxford.

[2] Acemoglu, D., Zilibotti, F., 1997. Was Prometheus unbound by chance? Risk, diversification, and growth. Journal of Political Economy, 105, 709-51.

[3] Aghion, P., Angeletos, G.M., Banerjee, A., Manova, K., 2010. Volatility and growth. Credit constraints and the composition of investment. Journal of Monetary Economics, $57,246-265$.

[4] Aghion, P., Banerjee, A., 2005. Volatility and growth. Oxford University Press, Oxford.

[5] Aghion, P., Saint-Paul, G., 1998. Virtues of bad times. Macroeconomic Dynamics, 2, 322-344.

[6] Aizenman, J., Pinto, B., 2005. Managing economic volatility and crises: A practitioner's guide oveview. In: Aizenman, J., Pinto B. (Eds.), Managing economic volatility and crises: A practitioner's guide. Cambridge University Press, Cambridge.

[7] Álvarez, L.J., Dhyne, E., Hoeberichts, M., Kwapil, C., Le Bihan, H., Lünnemann, P., Martins, F., Sabbatini, R., Stahl, H., Vermeulen, P., Vilmunen, J., 2006. Sticky Prices in the Euro Area: A Summary of New Micro-Evidence. Journal of the European Economic Association, 4(2-3), 575-584.

[8] Alvarez, F., Lippi, F., Paciello, L., 2011. Optimal price setting with observation and menu costs. Quarterly Journal of Economics, 126(4), 1909-1960.

[9] Andreou, E., Pelloni, A., Sensier, M., 2012. Is volatility good for growth? Evidence from the G7. CEIS Working Paper, No. 258.

[10] Andrés, J., Hernando, I., 1999. Does inflation harm economic growth? Evidence for the OECD. In: Feldstein, M. (Ed.), The Costs and Effects of Price Stability. The University of Chicago Press, Chicago.

[11] Annicchiarico, B., Corrado, L., Pelloni, A., 2011a. Long-term growth and short-term volatility: The labour market nexus. Manchester School, 79, 646-672.

[12] Annicchiarico, B., Pelloni, A., Rossi, L., 2011b. Endogenous growth, monetary shocks and nominal rigidities. Economics Letters, 113, 103-107. 
[13] Badinger, H., 2010. Output volatility and economic growth. Economics Letters, 106, 15-18.

[14] Barlevy, G., 2004. The cost of business cycles under endogenous growth. American Economic Review, 94, 964-990.

[15] Barlevy, G., 2007. On the cyclicality of research and development. American Economic Review, 97, 1131-1164.

[16] Barro, R., Sala-i-Martin, X., 2004. Economic growth. The MIT Press, Cambridge, MA.

[17] Bénassy, J.-P., 2002. The Macroeconomics of imperfect competition and nonclearing markets. The MIT Press, Cambridge, MA.

[18] Bénassy, J.-P., 2011. Macroeconomic theory. Oxford University Press, Oxford.

[19] Benigno, P., Ricci, L.A., Surico, P., 2010. Unemployment and productivity in the long run: The role of macroeconomic volatility. NBER Working Paper no. 16374.

[20] Bils, M., Klenow, P.J., 2004. Some evidence on the importance of sticky prices. Journal of Political Economy, 112, 947-985.

[21] Black, F., 1987. Business cycles and equilibrium. Basil Blackwell, New York.

[22] Blackburn, K., 1999. Can stabilisation policy reduce long-run growth? Economic Journal, 109, 67-77.

[23] Blackburn, K., Galindev, R., 2003. Growth, volatility and learning. Economics Letters, 79, 417-421.

[24] Blackburn, K., Pelloni, A., 2004. On the relationship between growth and volatility. Economics Letters, 83, 123-127.

[25] Blackburn, K., Pelloni, A., 2005. Growth, cycles, and stabilisation policy. Oxford Economic Papers, 57, 262-282.

[26] Blackburn, K., Varvarigos, D., 2008. Human capital accumulation and output growth in a stochastic environment. Economic Theory, 36, 435-452.

[27] Bredin, D., Fountas, S., 2009. Macroeconomic uncertainty and performance in the European Union. Journal of International Money and Finance, 28, 972-986.

[28] Canton, E., 2002. Business cycles in a two-sector model of endogenous growth. Economic Theory, 19, 477-492.

[29] Chatterjee, P., Shukayev, M. 2006. Are average growth rate and volatility related? Bank of Canada Working Paper no. 2006-24

[30] Comin,D., Gertler, M., 2006. Medium-term business cycles. American Economic Review, 96, 523-551. 
[31] Cukierman, A., Meltzer, A.,H., 1986. A theory of ambiguity, credibility, and inflation under discretion and asymmetric information. Econometrica, 54, 1099-1128.

[32] Dawson, J.W., Stephenson, E.F., 1997. The link between volatility and growth. Evidence from the States. Economics Letters, 55, 365-369.

[33] De Hek, P. 1999. On Endogenous growth under uncertainty. International Economic Review, 40, 727-744.

[34] Deveraux, M., 1989. A positive theory of inflation and inflation variance. Economic Inquiry, 27, 105.116.

[35] Dhyne, E., Alvarez, L.J., Le Bihan, H., Veronese, G., Dias, D., Hoffmann, J., Jonker, N., Lunnemann, P., Rumler, F., Vilmunen, J., 2006. Price changes in the Euro Area and the United States: Some facts from individual consumer price data. Journal of Economic Perspectives, 20, 171-192.

[36] Dickens, W.T., Goette, L. Groshen, E.L.,Holden, S., Messina, J., Schweitzer, M.E., Turunen, J., Ward, M.E., 2007. How wages change: Micro evidence from the international wage flexibility project. Journal of Economic Perspectives, 21, 195-214.

[37] Dotsey, M., Sarte, P.D., 2000. Inflation uncertainty and growth in a cash-in-advance economy. Journal of Monetary Economics, 45, 631-655.

[38] Elder, J., 2004. Another perspective on the effects of inflation uncertainty. Journal of Money, Credit and Banking, 36, 911-928.

[39] Evans, L., Kenc, T., 2003. Welfare cost of monetary and fiscal policy shocks. Macroeconomic Dynamics, 7, 212-238.

[40] Fatàs, A., 2000. Do business cycles cast long shadows? Short-run persistence and economic growth. Journal of Economic Growth, 5, 147-162.

[41] Fountas, S., Karanasos, M., Kim, J., 2006. Inflation uncertainty, output growth uncertainty and macroeconomic performance. Oxford Bulletin of Economics and Statistics, $68,319-343$.

[42] Francois, P., Lloyd-Ellis, H., 2003. Animal spirits through creative destruction, American Economic Review, 93, 530-550.

[43] Gaggl, P., Steindl, S., 2007. Business cycles and growth: A survey. WIFO Working Papers, No. 308.

[44] Galí, J., 2008. Monetary policy, inflation, and the business cycle, Princeton University Press, Princeton and Oxford.

[45] Galí, J., Gertler, M., López-Salido, J.D., 2007. Markups, gaps, and the welfare costs of business fluctuations. The Review of Economics and Statistics, 89, 44-59. 
[46] Grier, K.B., Henry, O.T., Olekalns, N., Shields, K., 2004. The asymmetric effects of uncertainty on inflation and output growth. Journal of Applied Econometrics, 19, 551565.

[47] Grier, K.B., Perry, M.J., 2000. The effects of real and nominal uncertainty on inflation and output growth: some Garch-M evidence. Journal of Applied Econometrics, 15, 45-58.

[48] Hnatkovska, V., Loayza, N., 2005. Volatility and growth. In: Aizenman, J., Pinto B. (Eds.), Managing economic volatility and vrises: A practitioner's guide. Cambridge University Press, Cambridge.

[49] Holden, S., Wulfsberg, F., 2008. Downward nominal wage rigidity in the OECD. The B.E. Journal of Macroeconomics, Berkeley Electronic Press, 8(1), pages 15.

[50] King, R., Rebelo, S., 1999. Resuscitating real business cycles. In: Taylor, J., Woodford, M. (Eds.), Handbook of Macroeconomics, vol. 1, Elsevier, Amsterdam, 927-1007.

[51] Klenow, P., Malin, B., (2011). Microeconomic evidence on price-setting, in B. Friedman, M. Woodford (Eds.), Handbook of Monetary Economics, Elsevier, Amsterdam, 231-284.

[52] Kose, M.A., Prasad, E.S., Terrones, M.E., 2005. Growth and volatility in an era of globalization. IMF Staff Papers, 52, Special Issue, 31-63.

[53] Kydland, F.E., Prescott, E.C., 1982. Time to build and aggregate fluctuations. Econometrica, 50, 1345-1370.

[54] Jones, C. I., 1995. R\&D-based models of endogenous growth. Journal of Political Economy, 103. 759-584.

[55] Jones, C.I., 2005. Growth and ideas. In: Aghion, P., Durlauf, S. (Eds.), Handbook of Economic Growth, vol. 1, Part B, Elsevier, Amsterdam, 1063-1111.

[56] Jones, C. I., Romer, P. M., 2010. The new Kaldor facts: Ideas, institutions, population, and human capital. American Economic Journal: Macroeconomics, American Economic Association, 2, 224-45.

[57] Jones, L.E., Manuelli, R.E., Siu, H., Stacchetti, E., 2005. Fluctuations in convex models of endogenous growth, I: Growth effects. Review of Economic Dynamics, 8, 780-804.

[58] Judson, R., Orphanides, A., 1999. Inflation, volatility and growth. International Finance, 2, 117-138.

[59] Long, J. B., Plosser, C. I., 1983. Real business cycles. Journal of Political Economy, 91, 39-69.

[60] Martin, P., Rogers, C.A., 1997. Stabilisation policy, learning-by-doing and economic growth. Oxford Economic Papers, 49, 152-166. 
[61] Martin, P., Rogers, C.A., 2000. Long-term growth and short-term economic instability. European Economic Review, 44, 359-381.

[62] Nakamura, E., Steinsson, J., 2008. Five facts about prices: A reevaluation of menu cost models. The Quarterly Journal of Economics, 123, 1415-1464,.

[63] Nelson, C. R., Plosser, C. I., 1982. Trends and random walks in macroeconomic time series: some evidence and implications. Journal of Monetary Economics, 10, 139-162.

[64] Pelloni, A., 1997. Nominal shocks, endogenous growth and the business cycle. Economic Journal, 107, 467-474.

[65] Ramey, G., Ramey, V.A., 1995. Cross-country evidence on the link between volatility and growth. American Economic Review, 85, 1138-1152.

[66] Romer, P.M., 1986. Increasing returns and long-run growth. Journal of Political Economy, 94, 1002-1037.

[67] Steindl, S. Tichy, G., 2009. Cycles and Growth: an Introduction, Empirica, 36, 159-164.

[68] Strulik, H., Prettner, K., Prskawetz, A., 2011. R\&D-based growth in the post-modern era, Leibniz Universität Hannover, Discussion Paper No. 457.

[69] Turnovsky, S. J., Chattopadhyay, P., 2003. Volatility and growth in developing economies: Some numerical results and empirical evidence. Journal of International Economics, 59, 267-295.

[70] Varvarigos, D., 2008. Inflation, variability, and the evolution of human capital in a model with transactions costs. Economics Letters, 98, 320-326.

[71] Walde, K., Woitek, U., 2004. R\&D expenditure in G7 countries and the implications for endogenous fluctuations and growth. Economics Letters, 82, 91-97.

[72] Walsh, C.E., 2003. Monetary theory and policy. The MIT Press, Cambridge, MA.

[73] Wang, P., Wen, Y. 2011. Volatility, growth, and welfare. Journal of Economic Dynamics and Control, 35, 1696-1709. 


\section{Appendix A: Derivations}

\section{Derivation of (21)-(22)}

To get the equilibrium nominal wage, after expressing $C_{t}$ in terms of $Y_{t}$ using (12), eliminate the nominal wage from (20) using (14). Simplifying, one obtains:

$$
E_{t-1} L_{t}^{v}=\frac{1}{\Theta}(\alpha+\phi)^{2} .
$$

Now, from (14) using (13) to eliminate $Y_{t}$ and $P_{t}$, one gets:

$$
L_{t}=\frac{(1+\gamma)(\alpha+\phi)}{\Theta} \frac{M_{t}}{W_{t}}
$$

This, combined with (44), gives us:

$$
W_{t}=\frac{(1+\gamma)(\alpha+\phi)}{\Theta} \bar{L}^{-1}\left(E_{t-1} M_{t}^{v}\right)^{1 / v},
$$

where we have used the fact that $W_{t}$ is a control variable at time $t-1$. Substituting back in (45):

$$
L_{t}=\bar{L} \frac{M_{t}}{\left(E_{t-1} M_{t}^{v}\right)^{1 / v}} .
$$

Recalling that $M_{t}=\mu_{t} M_{t-1}$ and (11) and exploiting the relationship between the mean of a lognormal variable and the moments of the underlying normal we get, from the last two expressions, (21) and (22) in the text.

\section{Derivation of (24)}

By definition, the wage markup $\mathcal{M U}_{t}^{W}$ is equal to

$$
\mathcal{M U}_{t}^{W}=\frac{\frac{W_{t}}{P_{t}}}{\frac{1+\gamma}{\gamma} L_{t}^{v-1} C_{t}} .
$$

Substituting (12), (13) in (48) to eliminate $C_{t}$ and $P_{t}$, then using (21) and (22), and simplifying yield:

$$
\mathcal{M U}_{t}^{W}=\frac{1}{\alpha+\phi} \frac{\exp v(v-1) \frac{\sigma_{\mu}^{2}}{2}}{\left[\exp \left(\varepsilon_{\mu, t}-\frac{\sigma_{\mu}^{2}}{2}\right)\right]^{v}},
$$

from which by taking expectations one gets (24).

\section{Derivation of (28)-(29)}

To find the reduced form expression for prices we proceed as follows. Consider equation (16) and express $C_{t}$ and $L_{t}$ in terms of $Y_{t}$, using respectively (12) and (6), to get:

$$
W_{t} L_{t}=\frac{1}{\alpha+\phi}\left(\frac{\Psi^{-1}}{\Omega_{t} A_{t-1}}\right)^{\frac{v}{\alpha+\phi}} Y_{t}^{\frac{v+\alpha+\phi}{\alpha+\phi}} P_{t} .
$$


We then plug the expression so found for $W_{t} L_{t}$ in (27). This gives us:

$$
P_{t}=\frac{\Theta}{(\alpha+\phi)^{2}\left(\Psi A_{t-1}\right)^{\frac{v}{\alpha+\phi}}} \frac{E_{t-1}\left[\left(\frac{1}{\Omega_{t}}\right)^{\frac{v}{\alpha+\phi}} Y_{t}^{\frac{v+\alpha+\phi}{\alpha+\phi}} P_{t}\right]}{E_{t-1} Y_{t}},
$$

or since $P_{t}$ is a control variable at time $t-1$,

$$
E_{t-1} Y_{t}=\frac{\Theta}{(\alpha+\phi)^{2}\left(\Psi A_{t-1}\right)^{\frac{v}{\alpha+\phi}}} E_{t-1}\left[\left(\frac{1}{\Omega_{t}}\right)^{\frac{v}{\alpha+\phi}} Y_{t}^{\frac{v+\alpha+\phi}{\alpha+\phi}}\right]
$$

Again using (13) to express $Y_{t}$ in terms of $M_{t}$ and solving for $P_{t}$ we obtain:

$$
P_{t}=\frac{\bar{L}^{-(\alpha+\phi)}(1+\gamma)}{\Psi A_{t-1}}\left\{\frac{E_{t-1}\left[\left(\frac{1}{\Omega_{t}}\right)^{\frac{v}{\alpha+\phi}}\left(M_{t}\right)^{\frac{v+\alpha+\phi}{\alpha+\phi}}\right]}{E_{t-1} M_{t}}\right\}^{\frac{\alpha+\phi}{v}} .
$$

Finally, exploiting the relationships between the moments of normal and lognormal variables we get the expression for $P_{t}$ in the text (28).

To get (29), use (13) to express $Y_{t}$ in terms of $M_{t}$, then substitute in (6) and finally plug (28).

\section{Derivation of (31)}

By definition, the price markup $\mathcal{M U}_{t}^{P}$ is equal to $P_{t}$ over the nominal marginal cost, that is

$$
\mathcal{M U}_{t}^{P}=\frac{P_{t}}{\frac{1}{\alpha+\phi} \frac{L_{t}}{Y_{t}} W_{t}} .
$$

Substitute the wage equation (16) in (54), simplify, recalling (12), and then plug (29). This yields

$$
\mathcal{M U}_{t}^{P}=\Theta\left\{\frac{\exp \left[2 \frac{\sigma_{\mu}^{2}}{2}+\frac{v}{\alpha+\phi}\left(\frac{\sigma_{\mu}^{2}}{2}+\frac{\sigma_{\Omega}^{2}}{2}\right)\right]}{\exp \left(\varepsilon_{\mu, t}-\varepsilon_{\Omega, t}\right)}\right\}^{\frac{v}{\alpha+\phi}}
$$

where we have used (3) and (11). From (55) by taking expectations one gets (31).

\section{Derivation of (36)-(38)}

First, combine (34) with (35) to eliminate $W_{t} / P_{t}$

$$
E_{t-1}\left(\frac{L_{t}}{C_{t}}\right)\left(E_{t-1} Y_{t}\right)=\frac{\Theta}{(\alpha+\phi)^{2}} \frac{1+\gamma}{\gamma}\left(E_{t-1} L_{t}^{v}\right)\left(E_{t-1} L_{t}\right) .
$$


As usual, express $C_{t}$ and $L_{t}$ in terms of $Y_{t}$, using (12) and (6) and then use the LM (13). Simplifying one obtains the following expression for the price preset at time $t$ :

$$
P_{t}=\frac{\bar{L}^{-(\alpha+\phi)}(1+\gamma)}{\Psi A_{t-1}}\left\{\frac{\left[E_{t-1}\left(\frac{M_{t}}{\Omega_{t}}\right)^{\frac{1}{\alpha+\phi}}\right]\left[E_{t-1}\left(\frac{M_{t}}{\Omega_{t}}\right)^{\frac{v}{\alpha+\phi}}\right]}{\left(E_{t-1} M_{t}\right)\left[E_{t-1}\left(\frac{1}{M_{t}}\left(\frac{M_{t}}{\Omega_{t}}\right)^{\frac{1}{\alpha+\phi}}\right)\right]}\right\}
$$

Finally, using (3) and (11) and exploiting the relationships between the moments of normal and lognormal variables we get the expression for $P_{t}$ in the text (36).

To find (38), substitute (36) into LM (13) to determine $Y_{t}$ and substitute it in (6).

Finally, (37) can be obtained from (34), expressing $Y_{t}$ in terms of $L_{t}$ using (6), substituting (36), (38) and taking expectations.

\section{Derivation of (40)-(41)}

The expected price markup (40) can be derived as follows. Use the LM (13) to express $Y_{t}$ in terms of $M_{t}$ and substitute in (54). Given the result, use (38) and (37) to get:

$$
\mathcal{M U}_{t}^{P}=\Theta \frac{\left(\frac{\mu_{t}}{\mu}\right)^{1-\frac{1}{\alpha+\phi}}\left(\frac{\Omega_{t}}{\Omega}\right)^{\frac{1}{\alpha+\phi}}}{\exp \left[-\frac{1}{(\alpha+\phi)^{2}}(\alpha+\phi+1)\left(\frac{\sigma_{\mu}^{2}}{2}+\frac{\sigma_{\Omega}^{2}}{2}\right)+\frac{1}{\alpha+\phi} \sigma_{\mu}^{2}\right]}
$$

and then take expectations.

Finally, substituting (12), (13) in (48) to eliminate $C_{t}$ and $P_{t}$, then using (38) and (38), simplifying yields:

$$
\mathcal{M U}_{t}^{W}=\frac{1}{\alpha+\phi} \frac{\mu}{\mu_{t}} \frac{\exp \left\{\frac{v-1}{(\alpha+\phi)^{2}}\left(\frac{\sigma_{\mu}^{2}}{2}+\frac{\sigma_{\Omega}^{2}}{2}\right)+\frac{1}{\alpha+\phi} \frac{1}{v}[1-(\alpha+\phi)] \sigma_{\mu}^{2}\right\}}{\left(\frac{\mu_{t} \Omega}{\mu \Omega_{t}}\right)^{\frac{v-1}{\alpha+\phi}} \exp \left[-\frac{v-1}{\alpha+\phi}\left(\frac{v+\alpha+\phi}{\alpha+\phi}\right)\left(\frac{\sigma_{\mu}^{2}}{2}+\frac{\sigma_{\Omega}^{2}}{2}\right)+\frac{v-1}{\alpha+\phi} B \frac{\sigma_{\mu}^{2}}{2}\right]},
$$

from which, taking expectations gives (41).

\section{Appendix B: Inflation variability under different price and wage settings}

In this Appendix we show how inflation variability is influenced by nominal and real uncertainty under different assumptions about wage and price settings, so demonstrating that under nominal rigidities the model predicts a negative relationship between inflation uncertainty and long-run growth. We also show that the model postulates a positive relationship between the average level and the variance of inflation. 


\section{Flexible prices and wages}

Starting from (13), and using (6), given (17), inflation is found to be:

$$
\frac{P_{t}}{P_{t-1}}=\frac{\mu}{g_{A}} \exp \left(\varepsilon_{\mu, t}-\varepsilon_{\Omega, t}-\frac{\sigma_{\mu}^{2}}{2}+\frac{\sigma_{\Omega}^{2}}{2}\right) .
$$

Therefore we have:

$$
E\left(\frac{P_{t}}{P_{t-1}}\right)=\frac{\mu}{g_{A}} \exp \sigma_{\Omega}^{2}
$$

We see that under flexible prices inflation is a convex function of the real shock, so that a mean preserving increase in real volatility gives rise to a higher average inflation.

As the variance of a variable is equal to the mean of its square minus the square of the mean, while

$$
E\left(\frac{P_{t}}{P_{t-1}}\right)^{2}=\left(\frac{\mu}{g_{A}}\right)^{2} \exp \left(\sigma_{\mu}^{2}+3 \sigma_{\Omega}^{2}\right),
$$

the variance of inflation immediately follows:

$$
\operatorname{Var}\left(\frac{P_{t}}{P_{t-1}}\right)=\left[E\left(\frac{P_{t}}{P_{t-1}}\right)\right]^{2}\left[\exp \left(\sigma_{\mu}^{2}+\sigma_{\Omega}^{2}\right)-1\right]
$$

So the variance of inflation depends positively on both real and nominal volatility, as well as on the mean of inflation.

\section{Preset wages}

Under the assumption of preset wages inflation is

$$
\frac{P_{t}}{P_{t-1}}=\frac{\mu}{g_{A}} \exp \left[(1-\alpha-\phi) \varepsilon_{\mu, t}+\alpha \varepsilon_{\mu, t-1}-\varepsilon_{\Omega, t}+(v \phi-1) \frac{\sigma_{\mu}^{2}}{2}+\frac{\sigma_{\Omega}^{2}}{2}\right] .
$$

Hence we have

$$
\begin{aligned}
E\left(\frac{P_{t}}{P_{t-1}}\right) & \left.=\frac{\mu}{g_{A}} \exp \left\{\left[(1-\alpha-\phi)^{2}+\alpha^{2}+v \phi-1\right)\right] \frac{\sigma_{\mu}^{2}}{2}+\sigma_{\Omega}^{2}\right\}, \\
E\left(\frac{P_{t}}{P_{t-1}}\right)^{2} & =\left(\frac{\mu}{g_{A}}\right)^{2} \exp \left\{\left[2(1-\alpha-\phi)^{2}+2 \alpha^{2}+(v \phi-1)\right] \sigma_{\mu}^{2}+3 \sigma_{\Omega}^{2}\right\},
\end{aligned}
$$

The variance of inflation is then

$$
\operatorname{Var}\left(\frac{P_{t}}{P_{t-1}}\right)=\left[E\left(\frac{P_{t}}{P_{t-1}}\right)\right]^{2}\left\{\exp \left[(1-\alpha-\phi)^{2} \sigma_{\mu}^{2}+\alpha^{2} \sigma_{\mu}^{2}+\sigma_{\Omega}^{2}\right]-1\right\},
$$

which is increasing in the mean of inflation and in both technological and money volatility. 


\section{Preset prices}

Under preset prices inflation is

$$
\frac{P_{t}}{P_{t-1}}=\frac{\mu}{g_{A}}\left[\frac{\exp \left(\varepsilon_{\mu, t-1}-\frac{\sigma_{\mu}^{2}}{2}\right)}{\exp \left(\varepsilon_{\Omega, t-1}-\frac{\sigma_{\Omega}^{2}}{2}\right)}\right]^{\frac{\alpha}{\alpha+\phi}} \exp \left[\frac{\phi}{\alpha+\phi}\left(1+\frac{v}{\alpha+\phi}\right)\left(\frac{\sigma_{\mu}^{2}}{2}+\frac{\sigma_{\Omega}^{2}}{2}\right)\right],
$$

which implies that

$$
\begin{aligned}
E\left(\frac{P_{t}}{P_{t-1}}\right) & =\frac{\mu}{g_{A}} \exp \left[\frac{\phi(v+\phi)}{(\alpha+\phi)^{2}} \frac{\sigma_{\mu}^{2}}{2}+\frac{2 \alpha(\alpha+\phi)+\phi(v+\phi)}{(\alpha+\phi)^{2}} \frac{\sigma_{\Omega}^{2}}{2}\right] \\
E\left(\frac{P_{t}}{P_{t-1}}\right)^{2} & =\left(\frac{\mu}{g_{A}}\right)^{2} \exp \left[\frac{\alpha^{2}+\phi(v+\phi)}{(\alpha+\phi)^{2}} \sigma_{\mu}^{2}+\frac{\alpha^{2}+2 \alpha(\alpha+\phi)+\phi(v+\phi)}{(\alpha+\phi)^{2}} \sigma_{\Omega}^{2}\right] .
\end{aligned}
$$

The variance is then equal to

$$
\operatorname{Var}\left(\frac{P_{t}}{P_{t-1}}\right)=\left[E\left(\frac{P_{t}}{P_{t-1}}\right)\right]^{2}\left\{\exp \left[\frac{\alpha^{2}}{(\alpha+\phi)^{2}}\left(\sigma_{\mu}^{2}+\sigma_{\Omega}^{2}\right)\right]-1\right\},
$$

which is positively related to average inflation and nominal and real uncertainty.

\section{Preset prices and wages}

When both prices and wages are preset inflation is

$$
\frac{P_{t}}{P_{t-1}}=\frac{\mu}{g_{A}}\left[\frac{\exp \left(\varepsilon_{\mu, t-1}-\frac{\sigma_{\mu}^{2}}{2}\right)}{\exp \left(\varepsilon_{\Omega, t-1}-\frac{\sigma_{\Omega}^{2}}{2}\right)}\right]^{\frac{\alpha}{\alpha+\phi}} \exp \left[\frac{\phi}{\alpha+\phi}\left(1+\frac{v}{\alpha+\phi}\right)\left(\frac{\sigma_{\mu}^{2}}{2}+\frac{\sigma_{\Omega}^{2}}{2}\right)-\phi \frac{B}{\alpha+\phi} \frac{\sigma_{\mu}^{2}}{2}\right] .
$$

Hence we have

$$
\begin{aligned}
& E\left(\frac{P_{t}}{P_{t-1}}\right)=\frac{\mu}{g_{A}} \exp \left\{\left[\phi \frac{v+\phi}{(\alpha+\phi)^{2}}-\phi \frac{B}{\alpha+\phi}\right] \frac{\sigma_{\mu}^{2}}{2}+\frac{2 \alpha(\alpha+\phi)+\phi(v+\phi)}{(\alpha+\phi)^{2}} \frac{\sigma_{\Omega}^{2}}{2}\right\}, \\
& E\left(\frac{P_{t}}{P_{t-1}}\right)^{2}=\left(\frac{\mu}{g_{A}}\right)^{2} \exp \left\{\begin{array}{c}
{\left[\frac{\alpha^{2}+\phi(v+\phi)}{(\alpha+\phi)^{2}}-\phi \frac{B}{\alpha+\phi}\right] \sigma_{\mu}^{2}+} \\
+\left[\frac{\alpha^{2}+2 \alpha(\alpha+\phi)+\phi(v+\phi)}{(\alpha+\phi)^{2}}\right] \sigma_{\Omega}^{2}
\end{array}\right\} \text {. }
\end{aligned}
$$

The variance of inflation is again increasing in average inflation and in both volatilities:

$$
\operatorname{Var}\left(\frac{P_{t}}{P_{t-1}}\right)=\left[E\left(\frac{P_{t}}{P_{t-1}}\right)\right]^{2}\left\{\exp \left[\frac{\alpha^{2}}{(\alpha+\phi)^{2}}\left(\sigma_{\mu}^{2}+\sigma_{\Omega}^{2}\right)\right]-1\right\} .
$$




\section{Appendix C: Scale effects}

Endogenous growth theory has stressed the role of ideas in economic development, which, due to their non-rivalry, introduce scale effects. In particular, when there are constant returns to the innovation activity with respect to the level of existing technical knowledge, as assumed in (2), a positive relationship between GDP per capita growth and the number of researchers arises. If these are a fixed fraction of the population, then growth should increase with the size of a country. However, Barro and Sala-i-Martin (2004, chap. 4) report no evidence of such scale effects using data from a cross section of countries, neither does Jones (1995) in the context of trends over time within countries. The cross sectional evidence at the level of individual nations has been questioned because economic integration lets countries of varying sizes draw from a shared pool of ideas, while the results of time series analyses depend on the length of time considered: in the longer run "the acceleration of population growth and per capita growth are striking bits of time series evidence that support the feedback between population and ideas" (Jones and Romer 2010 p. 235).

The debate on the empirical validity of the scale implication cannot be said to have reached a firm consensus (see Acemoglu 2009, chap. 13). Here, we want to underline that the message that volatility can have an impact on the accumulation of knowledge is not conditional on (strong) scale effects. We prove this assertion below by showing that when there are decreasing returns to the level of technical knowledge in the $\mathrm{R} \& \mathrm{D}$ sector, the effect of uncertainty on markups influences the long run level of technology, even if, in the absence of population growth, there is no sustained growth in the model. ${ }^{18}$ We consider the following 'metaproduction function':

$$
A_{t}(j)=\Omega_{t} A_{t-1}^{\chi} L_{R D, t}^{\phi}(j), \quad \chi<1,
$$

which substitutes (2) in the text. A similar function was proposed by Jones (1995) in his semi-endogenous growth model.

The firms' optimization problem at time $t, \forall t$, whether returns to knowledge are constant or decreasing, is static and past common knowledge $A_{t-1}$ enters the calculations as a constant. As a consequence, no matter the assumptions made on wage and price setting, $\chi$ does not affect the level of employment. For instance, in the case of flexible wages and prices, the only equations affected by the parameter $\chi$ and needed for the derivation of $L_{t}$, besides (76) of course, are (6), which becomes

$$
Y_{t}=\Psi \Omega_{t} A_{t-1}^{\chi} L_{t}^{\alpha+\phi}
$$

and (15) which becomes:

$$
L_{t}=\left(\frac{\Theta}{\alpha+\phi} \frac{W_{t}}{\Psi \Omega_{t} P_{t} A_{t-1}^{\chi}}\right)^{-\frac{1}{1-(\alpha+\phi)}} .
$$

\footnotetext{
${ }^{18}$ In fact, models have been developed in which, even with increasing returns in the innovation activity, no strong scale effects arise because the proliferation of products dilutes the productivity of research. In these models sustained growth is possible even without population growth. However, all these models rely on (alternative) restrictive assumptions and none can be said to have emerged as a benchmark (see Jones 2005 and Acemoglu 2009, chap. 13). As in such models weak scale effects are present, our educated guess is that in this class of models the impact of uncertainty through markups will be similar to what we have seen in this appendix.
} 
However, when (78) and (77) are combined with (12) and (16), they still deliver (17).

By plugging (17) in (76), under the assumption of symmetry of firms, given (7), which still holds, we find:

$$
A_{t}=\Omega_{t} A_{t-1}^{\chi}\left\{\frac{\phi}{\alpha+\phi}\left[\frac{(\alpha+\phi)^{2}}{\Theta}\right]^{1 / v}\right\}^{\phi} .
$$

With $\chi<1$ the model does not feature growth in the long run. In fact by iterating backward we can write:

$$
A_{t}=A_{0}^{\chi^{t}}\left[\left(\frac{\phi}{\alpha+\phi} \bar{L}\right)^{\phi}\right]^{\sum_{i=0}^{t-1} \chi^{i}} \prod_{i=0}^{t-1} \Omega^{\chi^{i}} \exp \left[\chi^{i}\left(\varepsilon_{\Omega, t-i}-\frac{\sigma_{\Omega}^{2}}{2}\right)\right] .
$$

$A_{t}$ is affected by a weighted average of lagged technology shocks, whose magnitudes of influence decline exponentially with the length of the lag. By exploiting the properties of the lognormal distribution of the shocks we can write:

$$
E\left(A_{t}\right)=A_{0}^{\chi^{t}}\left[\left(\frac{\phi}{\alpha+\phi} \bar{L}\right)^{\phi}\right]^{\sum_{i=0}^{t-1} \chi^{i}} \sum_{\Omega^{i=0}}^{t-1} \chi^{i} \exp \left[\frac{\sigma_{\Omega}^{2}}{2} \sum_{i=0}^{t-1} \chi^{i}\left(\chi^{i}-1\right)\right] .
$$

The limiting value of the mean of $A_{t}$ for $t \rightarrow \infty$ is then:

$$
E(A)=\left(\frac{\phi}{\alpha+\phi} \bar{L}\right)^{\frac{\phi}{1-\chi}} \Omega^{\frac{1}{1-\chi}} \exp \left(-\frac{\chi}{1-\chi^{2}} \frac{\sigma_{\Omega}^{2}}{2}\right) .
$$

Money shocks, and, as a consequence, their volatility do not have any influence on expected TFP. However, as $A_{t}$ is a strictly concave function of technology disturbances, past and current, their variance, by Jensen's inequality, does have a negative effect on $E(A)$.

\section{Preset wages}

Moving to the case of preset wages, the level of employment is again given by (22), as in its derivation combining (78) and (77) has the same effect as combining (15) and (6). We then have:

$$
A_{t}=\Omega_{t}\left(\frac{\phi}{\alpha+\phi}\right)^{\phi} A_{t-1}^{\chi}\left\{\bar{L} \frac{\mu_{t}}{\mu} \exp \left[-(v-1) \frac{\sigma_{\mu}^{2}}{2}\right]\right\}^{\phi} .
$$

We now have a positive effect of all current innovations on $A_{t}$. We can write:

$$
A_{t}=A_{0}^{\chi^{t}} K_{1}^{t-1} \prod_{i=0}^{\chi_{i}^{i}} \Omega_{t-i}^{\chi^{i}} \mu_{t-i}^{\phi \chi^{i}}
$$


where $K_{1} \equiv\left(\frac{\phi}{\alpha+\phi} \bar{L}\right)^{\phi}\left\{\frac{1}{\mu} \exp \left[-(v-1) \frac{\sigma_{\mu}^{2}}{2}\right]\right\}^{\phi}$. This shows lagged shocks have effects as well. The unconditional mean is now:

$$
E(A)=\left[\Omega\left(\frac{\phi}{\alpha+\phi} \bar{L}\right)^{\phi}\right]^{\frac{1}{1-\chi}} \exp \left(-\frac{\chi}{1-\chi^{2}} \frac{\sigma_{\Omega}^{2}}{2}-\phi \frac{v-\phi+v \chi}{1-\chi^{2}} \frac{\sigma_{\mu}^{2}}{2}\right) .
$$

The influence of the variance of the technological shocks on the long run level of $A$ is the same as with flexible wages, while a negative effect of the variance of money shocks appears, which is mediated through its effect on employment. In fact, a strong similarity emerges between the effect of money volatility on average growth in the model with constant returns to knowledge and its effect on the level of technology with decreasing returns, as can be seen by comparing (26) and (84). However, there is a difference, due to the fact that with $\chi=1$, only current money shocks have an effect on growth, (see eq. 25), while with $\chi<1$, the current level of technology is a concave function of past money shocks as well, which magnifies the negative impact of their variance.

\section{Preset prices}

In the case of preset prices, employment again does not depend on the parameter $\chi$ and is therefore still given by (29). By plugging (29) in (76), with symmetric firms we have rearranging and exploiting the structure of the shocks:

$$
A_{t}=A_{t-1}^{\chi} K_{2} \exp \left(\varepsilon_{\Omega, t}\right) \exp \left(\varepsilon_{\mu, t}-\varepsilon_{\Omega, t}\right)^{\frac{\phi}{\alpha+\phi}},
$$

with $K_{2} \equiv \Omega\left(\frac{\phi}{\alpha+\phi} \bar{L}\right)^{\phi} \exp \left(-\frac{\sigma_{\Omega}^{2}}{2}\right)\left\{\exp \left[-\frac{\sigma_{\mu}^{2}}{2}+\frac{\sigma_{\Omega}^{2}}{2}-\left(1+\frac{v}{\alpha+\phi}\right)\left(\frac{\sigma_{\mu}^{2}}{2}+\frac{\sigma_{\Omega}^{2}}{2}\right)\right]\right\}^{\frac{\phi}{\alpha+\phi}}$. We then get:

$$
E(A)=\left[\Omega\left(\frac{\phi}{\alpha+\phi} \bar{L}\right)^{\phi}\right]^{\frac{1}{1-\chi}} \exp \left\{\frac{-1}{1-\chi^{2}}\left[\begin{array}{c}
\left(\phi \frac{2 \alpha+\phi+v}{(\alpha+\phi)^{2}}+\chi \frac{(\alpha+\phi)^{2}+\phi v}{(\alpha+\phi)^{2}}\right) \frac{\sigma_{\Omega}^{2}}{2}+ \\
+\left(\phi \frac{2 \alpha+\phi+v}{(\alpha+\phi)^{2}}+\chi \phi \frac{2(\alpha+\phi)+v}{(\alpha+\phi)^{2}}\right) \frac{\sigma_{\mu}^{2}}{2}
\end{array}\right]\right\} .
$$

To interpret this equation, again it is useful to compare it with what can be thought of as its analogous under constant returns, i.e. (33). Clearly, the effect of the variance of the shocks on $E(A)$ is stronger than its effect on expected growth in the previous model.

On the one hand increased volatility leads to a reduced level of employment and to an increase in its volatility, exactly as seen in the text: algebraically the effect is captured by the coefficient $-\phi \frac{2 \alpha+\phi+v}{(\alpha+\phi)^{2}}$ which multiplies the variance of both shocks. This term appears both in (33) and in (86). However, when $\chi<1$, knowledge, being a concave function of its lagged value, is a concave function of all past shocks. This leads to geometrical compounding of the effect of volatility on the level of economic activity.

\section{Preset prices and wages}

For the last case, that of both price and wage setting, we just report the expected level of the technology, as the steps to get it and its economic interpretation are strictly analogous 
to those seen in the previous cases: the effect of volatility on this expectation is stronger because we have an effect through employment, which is the same as with $\chi=1$ and a further effect through the convexity of the 'meta production set':

$$
E(A)=\left[\Omega\left(\frac{\phi}{\alpha+\phi} \bar{L}\right)^{\phi}\right]^{\frac{1}{1-\chi}} \exp \left\{\frac{-1}{1-\chi^{2}}\left[\begin{array}{c}
\left(\phi \frac{2 \alpha+\phi+v}{(\alpha+\phi)^{2}}+\chi \frac{(\alpha+\phi)^{2}+\phi v}{(\alpha+\phi)^{2}}\right) \frac{\sigma_{\Omega}^{2}}{2}+ \\
+\left(\phi \frac{2 \alpha+\phi+v}{(\alpha+\phi)^{2}}+\chi \phi \frac{2(\alpha+\phi)+v}{(\alpha+\phi)^{2}}-\frac{(1+\chi) \phi}{\alpha+\phi} B\right) \frac{\sigma_{\mu}^{2}}{2}
\end{array}\right] \int_{(87)} .\right.
$$

Notice this expectation differs from (86) only from the term in $B$. 